\title{
Hemodynamic Characteristics and Predictors of Pulmonary Hypertension in Patients with Sickle Cell Disease
}

\author{
Melissa C. Caughey, MPH ${ }^{\mathrm{a}}$, Alan L. Hinderliter, MD ${ }^{\mathrm{a}}$, Susan K. Jones, RN ${ }^{\mathrm{a}}$, Sanjeev P. \\ Shah, MD $^{\mathrm{a}}$, and Kenneth I. Ataga, MD ${ }^{\mathrm{a}}$ \\ aUniversity of North Carolina at Chapel Hill, Chapel Hill, NC
}

\section{Abstract}

Pulmonary hypertension (PH) is a common comorbidity of sickle cell disease (SCD) with an associated increased mortality risk, but its etiology is not well-understood. To evaluate the hemodynamic characteristics, clinical predictors, and cardiovascular manifestations of elevated pulmonary arterial pressure in this population, we performed noninvasive hemodynamic assessments of 135 patients with SCD using Doppler echocardiography. A diagnosis of PH was based on gender-, age-, and body mass index (BMI)-specific normal reference ranges for tricuspid regurgitation jet velocities (TRV). A high TRV was noted in $34(25 \%)$ of patients. Pulmonary vascular resistance (PVR) was elevated in only 2 of the 34 patients (6\%) with suspected PH, but was significantly higher than in those with a normal TRV. In univariate regression, TRV correlated with age, BMI, left atrial pressure, and right ventricular stroke volume, and was negatively associated with hemoglobin and glomerular filtration rate. Left atrial pressure, right ventricular stroke volume, and hemoglobin remained independent predictors of TRV in a multivariate model. A higher TRV was also associated with larger right ventricular and right atrial chamber sizes and higher N-terminal pro-brain natriuretic peptide levels. Our results suggest that the mild elevation in TRV often observed in patients with SCD is rarely associated with a high PVR, and that multiple factors - including the compensatory high output state associated with anemia, pulmonary venous hypertension, and a pulmonary vasculopathy - may contribute to an elevated pulmonary arterial pressure in these patients.

\section{Keywords}

Pulmonary hypertension; sickle cell disease; echocardiography

\section{Introduction}

Pulmonary hypertension $(\mathrm{PH})$, diagnosed noninvasively by an elevation in the tricuspid regurgitation jet velocity (TRV), is a common comorbidity of sickle cell disease (SCD) with an associated increased mortality risk ${ }^{1-4}$. To gain insight into the hemodynamic characteristics, clinical predictors, and cardiac manifestations of $\mathrm{PH}$ in adult patients with $\mathrm{SCD}$, we examined echocardiographic data from a registry of patients followed in the University of North Carolina Sickle Cell Clinic. The objectives of this study were a) to

(C) 2012 Excerpta Medica, Inc. All rights reserved.

Corresponding author: Melissa C. Caughey, MPH, Division of Cardiology, Campus Box 7075, University of North Carolina at Chapel Hill, Chapel Hill, NC 27599-7075, Phone: (919) 843-0757, Fax: (919) 966-1743, caughey@ med.unc.edu.

Publisher's Disclaimer: This is a PDF file of an unedited manuscript that has been accepted for publication. As a service to our customers we are providing this early version of the manuscript. The manuscript will undergo copyediting, typesetting, and review of the resulting proof before it is published in its final citable form. Please note that during the production process errors may be discovered which could affect the content, and all legal disclaimers that apply to the journal pertain. 
noninvasively determine the prevalence of elevated pulmonary vascular resistance (PVR) in SCD patients with suspected $\mathrm{PH}, \mathrm{b}$ ) to compare the predictors of TRV to those found to be significant in the general population, and c) to assess the relationships between TRV and right ventricular and right atrial remodeling and function.

\section{Methods}

The 135 study subjects represent a cohort of clinically stable patients with SCD followed in the Sickle Cell Clinic at University of North Carolina Hospitals between 2004 and 2010. Each clinic patient was offered enrollment, with the exclusion of those with evidence of heart failure, acute painful episodes or episodes of acute chest syndrome within 4 weeks. Enrolled subjects were not required to have symptoms attributable to $\mathrm{PH}$, allowing prospective screenings without referral bias. The study was approved by the institutional review board at the University of North Carolina, and written informed consent was obtained from all participants.

Demographic and clinical characteristics of the study subjects were determined by interview and review of the medical record. Height, weight, blood pressure, and laboratory studies were measured on a single clinic visit. Body mass index (BMI) was calculated as weight/ height ${ }^{2}$, in units of $\mathrm{kg} / \mathrm{m}^{2}$. Seated blood pressure was measured with an automated device (Dinamap) following a minimum of 10 minutes of rest, and pulse pressure was calculated as the difference between systolic and diastolic pressures. Blood specimens were acquired for creatinine, hemoglobin, N-terminal pro-brain natriuretic peptide (NT-proBNP), and lactic dehydrogenase; glomerular filtration rate was estimated using the abbreviated Modification of Diet in Renal Disease formula. ${ }^{5}$

Echocardiograms were performed by 1 sonographer, using a protocol that included at least 3 cardiac cycles for each image. All studies were acquired with a Philips Sonos 5500 imaging platform, and were stored in a digital format for subsequent analysis. In 2006, Tissue Doppler Imaging was added to the protocol following a software upgrade.

All echocardiographic measurements were made in triplicate and averaged from representative beats, using offline echo analysis software. To minimize temporal drift in measurement tendencies, all measurements were batched and quantified at the study close by 1 analyst who was blinded to the clinical characteristics of the study subjects. Measurements of TR jet velocities were made separately by a single experienced cardiologist. The following echocardiographic parameters were measured: 1) TRV was measured by continuous wave Doppler signals acquired from the parasternal short axis, right ventricular inflow, and apical 4-chamber views. Only waveforms with well-defined "envelopes" were measured. Pulmonary arterial systolic pressure was estimated using the modified Bernoulli equation and an assumed right atrial pressure of $10 \mathrm{mmHg}$ (pulmonary arterial systolic pressure $\left.=4 \times \mathrm{TRV}^{2}+10\right) .{ }^{6}$ ) The velocity-time integral of systolic flow through the right ventricular outflow tract, a surrogate for right ventricular stroke volume ${ }^{7}$, was measured by pulsed wave Doppler with the sample volume positioned to obtain the "closing click" of the pulmonic valve. 3) PVR was estimated using the noninvasive PVR index developed by Abbas, et al ${ }^{8}$ : PVR index $=10 \times($ TRV/right ventricular outflow tract time-velocity integral). An index $>1.75$ was considered evidence of an elevated PVR. 4) Left and right ventricular areas were measured by planimetry from the apical 4-chamber view at end-diastole, tracing the endocardial borders and carefully avoiding papillary muscles and trabeculae. The right atrial area was traced by planimetry at mid-systole. 5) The ratio of mitral inflow to mitral annular early diastolic velocities (E/e') was calculated as an index of left atrial pressure ${ }^{9}$. The E-wave peak velocity was measured by pulsed wave Doppler of the transmitral diastolic flow, with the sample volume placed at the mitral leaflet 
tips. The e' peak velocity was measured by Tissue Doppler Imaging with the sample volume placed in the lateral mitral annulus. 6) The tricuspid annulus s' velocity, an indicator of right ventricular function ${ }^{10}$, was obtained by placing the Tissue Doppler sample volume in the lateral tricuspid annulus and measuring the peak systolic velocity.

Since the expected upper limits of pulmonary arterial systolic pressure are influenced by age and obesity, we based the diagnosis of PH on gender-, age-, and BMI-specific normal reference ranges derived from a large clinical database of echocardiographically normal subjects $^{6}$. A patient was classified as having "Suspected PH" if the TRV resulted in a calculated pulmonary arterial systolic pressure that exceeded the $95 \%$ confidence interval for both the gender- and age-specific reference range, and the gender- and BMI-specific reference range. This approach minimizes the tendency to overestimate the prevalence of $\mathrm{PH}$ due to marginally elevated TRV in overweight and older patients. Since TRV can usually be quantified in patients with significantly elevated pulmonary arterial pressure ${ }^{11}$, we categorized patients with unmeasureable TRV as having "No PH".

All statistical analyses were performed using SAS 9.2, with significance at the $\alpha=.05$ level (2-sided). Mean values for PVR were calculated after dichotomizing PH, using the normal gender-, age-, and BMI- specific reference ranges for calculated pulmonary arterial systolic pressure. Significance of the stratified analysis was determined by Wilcoxon rank sums. Linear correlations between TRV and echocardiographic, clinical, and laboratory variables were tested with Spearman regression. Relationships between TRV and all 2-diminsional echocardiographic measurements were tested by Spearman partial correlation, after controlling for body surface area. Spearman partial correlation controlling for glomerular filtration rate was used to test the relationship between NT-proBNP and TRV. Predictors of TRV were modeled with stepwise linear regression, with gender, age, and BMI forced into the model, and all parameter estimates standardized. Hemoglobin, lactate dehydrogenase, glomerular filtration rate, smoking, the E/e' ratio, pulse pressure, and the right ventricular outflow tract velocity-time integral were entered into the model, along with interaction terms. To meet assumptions of normality, TRV was log transformed.

\section{Results}

Characteristics of the study sample are summarized in Tables 1 and 2. Despite the relatively young sample, significant chronic comorbidities were observed in some subjects. Eighteen patients (13\%) had Stage 3 or 4 chronic kidney disease (glomerular filtration rate $15-59 \mathrm{ml} /$ $\left.\min / 1.73 \mathrm{~m}^{2}\right)$. Nineteen subjects $(14 \%)$ were hypertensive, based on a blood pressure measurement $>140 / 90 \mathrm{mmHg}$ in the clinic.

Tricuspid regurgitation could be detected and the velocity quantified in $104(77 \%)$ of the 135 screening echocardiograms; none of the remaining patients had echocardiographic findings (septal flattening or marked right ventricular enlargement and dysfunction) suggestive of PH. Of the 104 patients with quantifiable TRV, 34 had a peak TRV suggesting $\mathrm{PH}$, using the gender-, age-, and BMI-specific reference ranges for calculated pulmonary arterial systolic pressure. Thus, $\mathrm{PH}$ was suspected in $25 \%$ of patients. The distributions of the TRV values in the patients with and without suspected $\mathrm{PH}$ are illustrated in Figure 1. Ten subjects were classified as "No PH" despite a TRV $\geq 2.5 \mathrm{~m} / \mathrm{s}$, the partition value sometimes used to define PH. Most patients with suspected PH had mild elevations in TRV; $20(59 \%)$ had a TRV $<3.0 \mathrm{~m} / \mathrm{s}$. The average PVR index was significantly greater in patients with suspected PH than in those without $(1.4 \pm 0.2$ vs. $1.2 \pm 0.2, p=.0001)$, but was still well below the 1.75 cutoff for elevated PVR. Only 2 subjects with suspected PH (6\%), with TRV values of 3.0 and $3.9 \mathrm{~m} / \mathrm{s}$, respectively, had an elevated PVR index. 
Invasive measurements of pulmonary hemodynamics were examined in a convenience sample of 12 subjects who had suspected PH (mean TRV $=3.1 \mathrm{~m} / \mathrm{s}$ ) and who underwent right heart catheterization as part of their clinical evaluation within 3 years of the screening echocardiogram. PH (defined as mean pulmonary arterial pressure $\geq 25 \mathrm{mmHg}$ ) was confirmed in all but 1 of the 12 patients, and only a single patient had an elevated PVR (defined as PVR > 3 Wood units).

Linear relationships between TRV and a priori selected variables are shown in Table 3. TRV was correlated with age, BMI, E/e' ratio, and right ventricular outflow tract velocitytime integral, and negatively correlated with hemoglobin and glomerular filtration rate. There was a trend toward a linear association between TRV and lactate dehydrogenase that did not reach statistical significance. As shown in Table 4, left atrial pressure, right ventricular stroke volume, and hemoglobin (at a borderline level of statistical significance) were predictors of TRV in a multivariate regression model that explained $49 \%$ of the variability. For every 1.0 unit increase in E/e', the TRV increased by $12 \%$. For every $1.0 \mathrm{~g} /$ $\mathrm{dL}$ increase in hemoglobin, the TRV decreased by $13 \%$. And, for every $1.0 \mathrm{~cm}$ increase in the right ventricular outflow tract velocity-time integral, the TRV increased by $6 \%$.

Relationships between TRV and indices of right heart structure and function and NTproBNP are shown in Table 5. Higher TRV was associated with larger right ventricular and right atrial chamber sizes, more severe tricuspid regurgitation, and greater values of NTproBNP. TRV was not significantly correlated with tricuspid annulus s' velocity. NTproBNP was related to right ventricular area $(\mathrm{r}=0.18, \mathrm{p}=0.05)$ and right atrial area $(\mathrm{r}=$ $0.16, p=0.08)$, as well as mitral $\mathrm{E} / \mathrm{e}^{\prime}(\mathrm{r}=0.34, \mathrm{p}=0.0008)$ after adjusting for body surface area and glomerular filtration rate; the relationships with right ventricular area $(r=0.22, p=$ $0.04)$ and right atrial area $(r=0.18, \mathrm{p}=0.09)$ remained similar after correcting for $\mathrm{E} / \mathrm{e}^{\prime}$.

\section{Discussion}

Our data suggest that most adult patients with SCD and suspected PH, based on gender-, age-, and BMI-specific reference values for TRV, have a normal PVR. A high TRV in SCD patients is associated with older age, greater BMI, and an elevated left atrial pressure, as in the general population ${ }^{12}$, but also with anemia and an elevated right ventricular stroke volume. Although the elevation in TRV observed in patients with SCD is often mild, it is nonetheless associated with remodeling of the right ventricle and right atrium and an elevated NT-proBNP.

Our reported suspected $\mathrm{PH}$ prevalence of $25 \%$ is consistent with data from previous studies that have based this diagnosis on an elevated TRV ${ }^{1-3}$, including a previous report from our group that included many patients in the present cohort ${ }^{1}$. Whether PH can be confidently diagnosed by Doppler echocardiography is controversial, however. Estimation of PASP using the TRV gained widespread acceptance as a valuable method of screening for PH after early publications demonstrating a close relationship between Doppler and invasive measurements ${ }^{13}, 14$. Several subsequent studies have questioned the accuracy of this technique $^{7,15}$. In a recent prospective, multicenter study in which patients with SCD and suspected PH underwent right heart catheterization, only 24 of the 96 patients $(25 \%)$ with a $\mathrm{TRV} \geq 2.5 \mathrm{~m} / \mathrm{s}$ had a mean pulmonary arterial pressure $\geq 25 \mathrm{mmHg}^{16}$.

The limited positive predictive value of an elevated TRV may be explained in part by inaccuracies of the Doppler measurement and physiologic variations in pulmonary hemodynamics. Many patients with SCD have TRV values that are marginally elevated, and a small difference in the measurement can lead to a change in classification. Moreover, the TRV estimates pulmonary arterial systolic pressure, while the invasive diagnosis of PH is based on the mean pulmonary arterial pressure. The partition value of TRV used to define 
$\mathrm{PH}$ is also an important factor. Although a threshold TRV of $\geq 2.5 \mathrm{~m} / \mathrm{s}$ is often used, otherwise healthy individuals who are older or obese may have higher values ${ }^{6}$. Indeed, data from a random sample of Olmsted County, Minnesota suggest that $25 \%$ of the general population older than 45 years has a TRV $\geq 2.5 \mathrm{~m} / \mathrm{s}^{12}$. We propose that basing the noninvasive diagnosis of PH on gender-, age-, and BMI-specific reference values for TRV is preferable to using a fixed velocity of $2.5 \mathrm{~m} / \mathrm{s}$ in cohort studies of patients with SCD. This strategy identifies a high-risk subset of patients with greater TRV than expected in the general population, most of whom have $\mathrm{PH}$ on right heart catheterization.

The pathogenesis of $\mathrm{PH}$ in patients with SCD is complex. The compensatory high output state resulting from chronic anemia may contribute to an elevated pulmonary arterial pressure ${ }^{17-20}$. Pulmonary venous hypertension as a manifestation of left ventricular dilatation and eccentric hypertrophy may be a significant factor in some patients ${ }^{21}$. Hemolysis is also believed to play an important role, leading to nitric oxide depletion, endothelin-1 release, and platelet activation, and ultimately resulting in a vasculopathy characterized by endothelial dysfunction, increased vascular tone, inflammation, hypercoagulability, and vascular remodeling ${ }^{21-24}$.

The relations between TRV and clinical and laboratory parameters observed in our cohort are consistent with multiple pathogenic mechanisms contributing to $\mathrm{PH}$ in patients with SCD. As in the general population, age and BMI are correlated with TRV. The strong, independent associations of TRV with right ventricular outflow tract velocity-time integral, a measure of right ventricular stroke volume, and the Doppler E/e' ratio, an index of left atrial pressure, support the importance of both high cardiac output and pulmonary venous hypertension in the pathogenesis of $\mathrm{PH}$ in this population. A possible role for hemolysis is suggested by the negative correlation of TRV with hemoglobin, and an association of borderline statistical significance with lactate dehydrogenase.

To our knowledge, this is the first study to noninvasively examine the prevalence of elevated PVR in adult SCD patients prospectively screened for PH by Doppler echocardiography. As noted previously in pediatric populations ${ }^{17,18}$, we found that a high TRV in our adult patients with SCD was rarely associated with an elevated PVR. Similarly, Parent, et al ${ }^{16}$ found an elevated PVR on right heart catheterization in only a small proportion of patients with high TRV. The normal values for PVR in our patients with suspected PH do not necessarily imply an absence of pulmonary vascular disease; the PVR in these patients is higher than in those with normal pulmonary arterial pressures, and may be inappropriately high in association with a high cardiac output. Nonetheless, our findings suggest an important - and perhaps predominant - role for the high output state associated with anemia in the pathogenesis of PH in adult patients with SCD. While an elevated pulmonary arterial pressure may be commonplace in SCD, pulmonary arterial hypertension -- defined by consensus as an elevated pulmonary arterial pressure in association with a normal pulmonary arterial wedge pressure and a PVR $>3$ Wood units $^{25}$-- is found in a relatively small minority of these patients.

Our study has some limitations that deserve acknowledgement. Our subjects were recruited from a specialty clinic at a tertiary care medical center, and may not be representative of all patients with SCD. As noted previously, echocardiography is not the "gold standard" technique for assessing pulmonary arterial pressures or PVR, but is more feasible than right heart catheterization for large-scale screenings. The noninvasive PVR index has not been validated in SCD patients or in other populations characterized by a high cardiac output. As with all cross-sectional studies, this analysis can demonstrate associations, but cannot prove causation. 


\section{Acknowledgments}

This study was supported by National Institutes of Health grants UL1RR025747, HL79915 and HL094592

\section{References}

1. Ataga KI, Sood N, De Gent G, Kelly E, Henderson AG, Jones S, Strayhorn D, Lail A, Lieff S, Orringer EP. Pulmonary hypertension in sickle cell disease. Am J Med. 2004; 117:665-669. [PubMed: 15501204]

2. De Castro LM, Jonassaint JC, Graham FL, Ashley-Koch A, Telen MJ. Pulmonary hypertension associated with sickle cell disease: clinical and laboratory endpoints and disease outcomes. Am J Hematol. 2008; 83:19-25. [PubMed: 17724699]

3. Gladwin MT, Sachdev V, Jison ML, Shizukuda Y, Plehn JF, Minter K, Brown B, Coles WA, Nichols JS, Ernst I, Hunter LA, Blackwelder WC, Schechter AN, Rodgers GP, Castro O, Ognibene FP. Pulmonary hypertension as a risk factor for death in patients with sickle cell disease. N Engl J Med. 2004; 350:886-895. [PubMed: 14985486]

4. Ataga KI, Moore CG, Jones S, Olajide O, Strayhorn D, Hinderliter A, Orringer EP. Pulmonary hypertension in patients with sickle cell disease: a longitudinal study. Br J Haematol. 2006; 134:109-115. [PubMed: 16803576]

5. Levey AS, Bosch JP, Lewis JB, Greene T, Rogers N, Roth D. A more accurate method to estimate glomerular filtration rate from serum creatinine: a new prediction equation. Modification of Diet in Renal Disease Study Group. Ann Intern Med. 1999; 130:461-470. [PubMed: 10075613]

6. McQuillan BM, Picard MH, Leavitt M, Weyman AE. Clinical correlates and reference intervals for pulmonary artery systolic pressure among echocardiographically normal subjects. Circulation. 2001; 104:2797-2802. [PubMed: 11733397]

7. Fisher MR, Forfia PR, Chamera E, Housten-Harris T, Champion HC, Girgis RE, Corretti MC, Hassoun PM. Accuracy of Doppler echocardiography in the hemodynamic assessment of pulmonary hypertension. Am J Respir Crit Care Med. 2009; 179:615-621. [PubMed: 19164700]

8. Abbas AE, Fortuin FD, Schiller NB, Appleton CP, Moreno CA, Lester SJ. A simple method for noninvasive estimation of pulmonary vascular resistance. J Am Coll Cardiol. 2003; 41:1021-1027. [PubMed: 12651052]

9. Nagueh SF. Echocardiographic assessment of left ventricular relaxation and cardiac filling pressures. Curr Heart Fail Rep. 2009; 6:154-159. [PubMed: 19723456]

10. Meluzin J, Spinarova L, Bakala J, Toman J, Krejci J, Hude P, Kara T, Soucek M. Pulsed Doppler tissue imaging of the velocity of tricuspid annular systolic motion; a new, rapid, and non-invasive method of evaluating right ventricular systolic function. Eur Heart J. 2001; 22:340-348. [PubMed: 11161953]

11. Berger M, Haimowitz A, Van Tosh A, Berdoff RL, Goldberg E. Quantitative assessment of pulmonary hypertension in patients with tricuspid regurgitation using continuous wave Doppler ultrasound. J Am Coll Cardiol. 1985; 6:359-365. [PubMed: 4019921]

12. Lam CS, Borlaug BA, Kane GC, Enders FT, Rodeheffer RJ, Redfield MM. Age-associated increases in pulmonary artery systolic pressure in the general population. Circulation. 2009; 119:2663-2670. [PubMed: 19433755]

13. Yock PG, Popp RL. Noninvasive estimation of right ventricular systolic pressure by Doppler ultrasound in patients with tricuspid regurgitation. Circulation. 1984; 70:657-662. [PubMed: 6478568]

14. Currie PJ, Seward JB, Chan KL, Fyfe DA, Hagler DJ, Mair DD, Reeder GS, Nishimura RA, Tajik AJ. Continuous wave Doppler determination of right ventricular pressure: a simultaneous Doppler catheterization study in 127 patients. J Am Coll Cardiol. 1985; 6:750-756. [PubMed: 4031289]

15. Arcasoy SM, Christie JD, Ferrari VA, Sutton MS, Zisman DA, Blumenthal NP, Pochettino A, Kotloff RM. Echocardiographic assessment of pulmonary hypertension in patients with advanced lung disease. Am J Respir Crit Care Med. 2003; 167:735-740. [PubMed: 12480614]

16. Parent F, Bachir D, Inamo J, Lionnet F, Driss F, Loko G, Habibi A, Bennani S, Savale L, Adnot S, Maitre B, Yaici A, Hajji L, O'Callaghan DS, Clerson P, Girot R, Galacteros F, Simonneau G. A 
hemodynamic study of pulmonary hypertension in sickle cell disease. N Engl J Med. 2011; 365:44-53. [PubMed: 21732836]

17. Chaudry RA, Cikes M, Karu T, Hutchinson C, Ball S, Sutherland G, Rosenthal M, Bush A, Crowley S. Paediatric sickle cell disease: pulmonary hypertension but normal vascular resistance. Arch Dis Child. 2011; 96:131-136. [PubMed: 21030373]

18. Dham N, Ensing G, Minniti C, Campbell A, Arteta M, Rana S, Darbari D, Nouraie M, Onyekwere O, Lasota M, Kato GJ, Gladwin MT, Castro O, Gordeuk V, Sable C. Prospective echocardiography assessment of pulmonary hypertension and its potential etiologies in children with sickle cell disease. Am J Cardiol. 2009; 104:713-720. [PubMed: 19699350]

19. Aessopos A, Kati M, Farmakis D. Heart disease in thalassemia intermedia: a review of the underlying pathophysiology. Haematologica. 2007; 92:658-665. [PubMed: 17488690]

20. Aessopos A, Farmakis D, Trompoukis C, Tsironi M, Moyssakis I, Tsaftarides P, Karagiorga M. Cardiac involvement in sickle beta-thalassemia. Ann Hematol. 2009; 88:557-564. [PubMed: 19107483]

21. Farmakis D, Aessopos A. Pulmonary hypertension associated with hemoglobinopathies: prevalent but overlooked. Circulation. 2011; 123:1227-1232. [PubMed: 21422398]

22. Gladwin MT, Vichinsky E. Pulmonary complications of sickle cell disease. N Engl J Med. 2008; 359:2254-2265. [PubMed: 19020327]

23. Gladwin MT, Lancaster JR Jr, Freeman BA, Schechter AN. Nitric oxide's reactions with hemoglobin: a view through the SNO-storm. Nat Med. 2003; 9:496-500. [PubMed: 12724752]

24. Aessopos A, Farmakis D, Tsironi M, Diamanti-Kandarakis E, Matzourani M, Fragodimiri C, Hatziliami A, Karagiorga M. Endothelial function and arterial stiffness in sickle-thalassemia patients. Atherosclerosis. 2007; 191:427-432. [PubMed: 16712855]

25. McLaughlin VV, Archer SL, Badesch DB, Barst RJ, Farber HW, Lindner JR, Mathier MA, McGoon MD, Park MH, Rosenson RS, Rubin LJ, Tapson VF, Varga J, Harrington RA, Anderson JL, Bates ER, Bridges CR, Eisenberg MJ, Ferrari VA, Grines CL, Hlatky MA, Jacobs AK, Kaul S, Lichtenberg RC, Lindner JR, Moliterno DJ, Mukherjee D, Pohost GM, Rosenson RS, Schofield RS, Shubrooks SJ, Stein JH, Tracy CM, Weitz HH, Wesley DJ. ACCF/AHA. ACCF/AHA 2009 expert consensus document on pulmonary hypertension: a report of the American College of Cardiology Foundation Task Force on Expert Consensus Documents and the American Heart Association: developed in collaboration with the American College of Chest Physicians, American Thoracic Society, Inc. and the Pulmonary Hypertension Association. Circulation. 2009; 119:22502294. [PubMed: 19332472] 

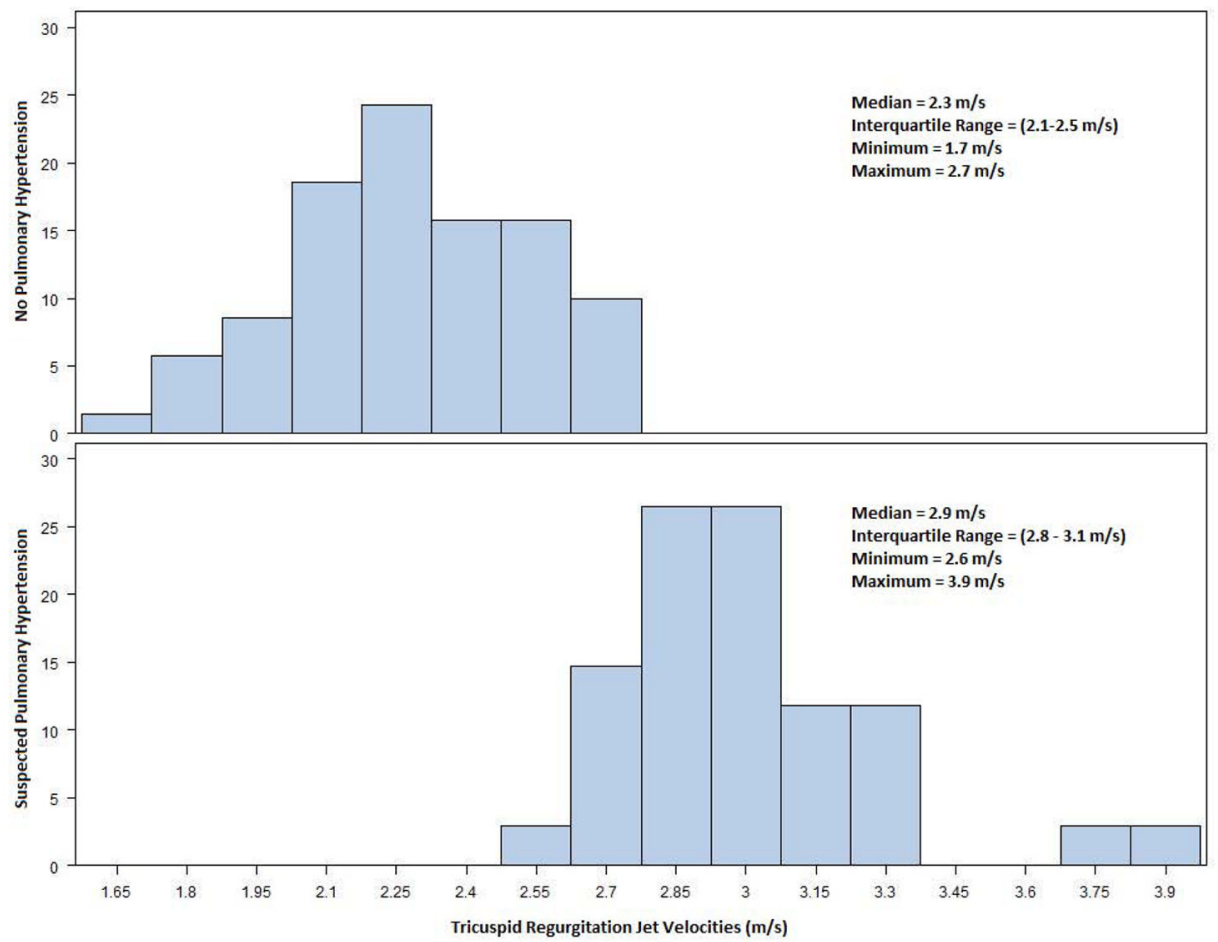

Figure 1.

Distributions of tricuspid regurgitation jet velocities, stratified by "Suspected Pulmonary Hypertension" and "No Pulmonary Hypertension" classification. 
Table 1

Characteristics of the study population

\begin{tabular}{|lcc|}
\hline Characteristic & N & Number (\%) or Mean \pm S.D. \\
\hline Male & 135 & $49(36 \%)$ \\
\hline Black & 135 & $133(99 \%)$ \\
\hline Age (years) & 135 & $39 \pm 13$ \\
\hline Smoker & 135 & $43(32 \%)$ \\
\hline Body mass index $\left(\mathrm{kg} / \mathrm{m}^{2}\right)$ & 135 & $26.6 \pm 7.0$ \\
\hline Creatinine $(\mathrm{mg} / \mathrm{dL})$ & 135 & $1.0 \pm 0.7$ \\
\hline Glomerular filtration rate $\left(\mathrm{mL} / \mathrm{min} / 1.73 \mathrm{~m}^{2}\right)$ & 135 & $124 \pm 57$ \\
\hline Hemoglobin $(\mathrm{g} / \mathrm{dL})$ & 135 & $9.0 \pm 1.8$ \\
\hline Systolic blood pressure $(\mathrm{mmHg})$ & 135 & $124 \pm 16$ \\
\hline Diastolic blood pressure $(\mathrm{mmHg})$ & 135 & $71 \pm 12$ \\
\hline Pulse pressure $(\mathrm{mmHg})$ & 135 & $53 \pm 13$ \\
\hline N-terminal pro-brain natriuretic peptide $(\mathrm{pg} / \mathrm{mL})$ & 131 & $392 \pm 1254$ \\
\hline Lactate dehydrogenase $(\mathrm{U} / \mathrm{L})$ & 132 & $989 \pm 480$ \\
\hline
\end{tabular}


Table 2

Echocardiographic values for the study population

\begin{tabular}{|lcc|}
\hline Characteristic & N & Mean \pm S.D. \\
\hline Tricuspid regurgitation velocity $(\mathrm{m} / \mathrm{s})$ & 104 & $2.5 \pm 0.4$ \\
\hline Estimated pulmonary arterialsystolic pressure $(\mathrm{mmHg})$ & 104 & $36 \pm 9$ \\
\hline Right ventricular outflow tract velocity-time integral $(\mathrm{cm})$ & 134 & $20.1 \pm 3.7$ \\
\hline Pulmonary vascular resistance index & 103 & $1.2 \pm 0.2$ \\
\hline E/e' ratio & 95 & $8.0 \pm 3.7$ \\
\hline Tricuspid annulus s' $(\mathrm{cm} / \mathrm{s})$ & 92 & $15.0 \pm 2.5$ \\
\hline Tricuspid regurgitation jet area $\left(\mathrm{cm}^{2}\right)$ & 126 & $4.9 \pm 3.1$ \\
\hline Right ventricular area $\left(\mathrm{cm}^{2}\right)$ & 130 & $23.4 \pm 4.5$ \\
\hline Right atrial area $\left(\mathrm{cm}^{2}\right)$ & 133 & $17.1 \pm 3.9$ \\
\hline Left ventricular area $\left(\mathrm{cm}^{2}\right)$ & 131 & $42.7 \pm 6.4$ \\
\hline
\end{tabular}


Table 3

Simple correlations of tricuspid regurgitation jet velocity with selected clinical and echocardiographic variables

\begin{tabular}{|lccc|}
\hline Variable & $\mathbf{N}$ & $\mathbf{r}$ & $\mathbf{p}$ \\
\hline Age, years & 104 & 0.35 & 0.0003 \\
\hline Body mass index $\left(\mathrm{kg} / \mathrm{m}^{2}\right)$ & 104 & 0.26 & 0.007 \\
\hline Hemoglobin $(\mathrm{g} / \mathrm{dL})$ & 104 & -0.22 & 0.02 \\
\hline Lactate dehydrogenase $(\mathrm{U} / \mathrm{L})$ & 102 & 0.17 & 0.08 \\
\hline Glomerular filtration rate $\left(\mathrm{mL} / \mathrm{min} / 1.73 \mathrm{~m}^{2}\right)$ & 104 & -0.47 & $<.0001$ \\
\hline E/e' ratio & 76 & 0.60 & $<.0001$ \\
\hline Right ventricular outflow tract velocity-time integral $(\mathrm{cm})$ & 103 & 0.39 & $<.0001$ \\
\hline Pulse pressure $(\mathrm{mmHg})$ & 104 & 0.13 & 0.2 \\
\hline
\end{tabular}


Table 4

Results of multivariable regression model for predictors of tricsupid regurgitation jet velocity

\begin{tabular}{|lccc|}
\hline Variable & Standard Deviation & Standardized Estimate & p \\
\hline Age (years) & 13.8 & 0.145 & 0.1 \\
\hline Gender & 0.5 & 0.114 & 0.2 \\
\hline Body mass index $\left(\mathrm{kg} / \mathrm{m}^{2}\right)$ & 5.6 & 0.158 & 0.1 \\
\hline E/e' ratio & 4.1 & 0.484 & $<.0001$ \\
\hline Hemoglobin $(\mathrm{g} / \mathrm{dL})$ & 1.6 & -0.204 & 0.06 \\
\hline Right ventricular outflow tract time-velocity integral $(\mathrm{cm})$ & 3.0 & 0.192 & 0.03 \\
\hline
\end{tabular}

$\mathrm{N}=76 \mathrm{R}^{2}=49 \%$ 
Table 5

Spearman correlations with tricuspid regurgitation jet velocity

\begin{tabular}{|lccc|}
\hline Variable & N & r & p \\
\hline Right ventricular area $\left(\mathrm{cm}^{2}\right)^{*}$ & 102 & 0.18 & 0.06 \\
\hline Right atrial area $\left(\mathrm{cm}^{2}\right)^{*}$ & 103 & 0.27 & 0.007 \\
\hline Tricuspid annular s' velocity $(\mathrm{cm} / \mathrm{s})$ & 73 & -0.18 & 0.1 \\
\hline Tricuspid regurgitant jet area $\left(\mathrm{cm}^{2}\right)$ & 98 & 0.25 & 0.01 \\
\hline N-terminal pro-brain natriuretic peptide $(\mathrm{pg} / \mathrm{mL})^{\dagger}$ & 101 & 0.31 & 0.002 \\
\hline
\end{tabular}

* Controlling for body surface area

${ }^{\dagger}$ Controlling for glomerular filtration rate 